\title{
Esdras-Neemias \\ e a gestão da memória ${ }^{1}$
}

\section{Samuel de Barros Gandara}

DOI: 10.11606/issn.2318-8855.v10i2p191-220

Resumo: Esse artigo tem por objetivo fazer breves apontamentos das contribuições que os estudos em torno da relação entre trauma, memória e narrativa vêm proporcionando para o campo de pesquisa historiográfica dos reinos do Antigo Israel e de Judá. Para isso, tentará demonstrar que a narrativa de reconstrução do templo de Jerusalém, em Esdras 1-6, é um suporte para modalidades de conflito em torno do poder da memória na mediação das relações sociais dos grupos de judaítas no período pós-exilico.

Palavras-chave: Esdras-Neemias; Judaísmo do Segundo Templo; Memória; Trauma.

\footnotetext{
${ }^{1}$ Esse artigo faz parte de resultados obtidos através da uma pesquisa de Iniciação Científica (No Processo: 2018/23943-1) financiada pela Fundação de Amparo à Pesquisa do Estado de São Paulo (FAPESP). Agradeço a FAPESP pela oportunidade de desenvolver a pesquisa com financiamento. Também agradeço meu orientador Prof. Marcelo Rede pelos conselhos e ensinamentos e aos colegas do Laboratório do Antigo Oriente Próximo (LAOP - USP), em especial ao Dr. Matheus Treuk e ao Dr. Leandro Ranieri que me acompanharam de perto ao longo dessa pesquisa. Contato: samuel.gandara@usp.br
} 


\section{artigos}

\section{Samuel de Barros Gandara}

\section{Esdras-Neemias: trauma, memória e narrativa}

Em termos gerais, o material de Esdras-Neemias é uma documentação literária da Bíblia Hebraica que têm ganhado diferentes abordagens na historiografia do Antigo Israel e Judá. Essa diversidade de abordagens é fruto de uma intensa renovação metodológica no campo dos estudos bíblicos, em que, pelo menos nas últimas duas décadas, existem propostas de abertura do campo de pesquisa às demais ciências das humanidades. Dentro do contexto de pesquisa historiográfica, essa maior proximidade com ferramentas distintas de disciplinas como a Antropologia, a Sociologia e os Estudos Culturais tornaram um campo, outrora predominantemente marcado por preocupações filológicas e exegéticas, mais diversificado. Esse processo de abertura contribuiu de maneira significativa para empreender uma historicização do material literário bíblico. Sendo assim, o esforço metodológico para o tratamento historiográfico do texto bíblico possui uma natureza dupla: reavaliar as narrativas bíblicas a partir de sua composição - marcada por diferentes comunidades que formaram seus múltiplos processos redacionais e editoriais, ao longo de distintos contextos históricos; e, identificar, para além de dimensões teológicas, elementos socioculturais e políticos que dizem respeito a espaços de poder em constante (re)negociação na sociedade que produziu esse material literário.

Tendo isso como ponto de partida, ao observarmos o escopo dos estudos bíblicos que trata do período exílico e pós-exilico, nota-se um crescente interesse em avaliar o material literário desse período como uma forma de narrativa de resposta, impulsionada pelas consequências do contato com o Império Babilônico ${ }^{1}$ Esse período que compreende a primeira onda de deportação, no ano 609 a.E.C, passando pela

\footnotetext{
${ }^{1}$ Para uma bibliografia específica, ver: JANZEN, 2019; REDE, 2019; BERLEJUNG, 2017; BOASE, 2016.
} 


\section{artigos}

\section{Esdras-Neemias e a gestão da memória}

destruição de Jerusalém em 586 a.E.C, dará início a uma intensa reorganização de Judá. Igualmente importante, a partir do ano 538 a.E.C, a ascensão do Império Persa Aquemênida e seus incursos na região Sírio-Palestina, deram continuidade às transformações da região, inclusive possibilitando fluxos migratórios de judaítas, que puderam retornar a Judá. Isto posto, é possível afirmar que as diferentes narrativas bíblicas emergentes nesses recortes temporais são fruto de um complexo jogo de forças políticas e econômicas.

Sob essa perspectiva, o material bíblico ganha as atenções de investigações que tratam da região levantina durante os períodos babilônico e persa, pois se reconhece que tais eventos históricos foram significativos para a reformulação da sociedade judaíta, possibilitando a criação de um material diversificado de memória social e cultural, narrativas de fundação e retorno, negociações identitárias e inúmeras reflexões teleológicas e teológicas. Somado a isso, faz parte desse campo de pesquisa, discutir os impactos da destruição do templo e da cidade de Jerusalém na organização social da província de Judá, também reconhecendo no período a emergência de novas expressões de religiosidade mediante a ausência da principal estrutura ritualística do período monárquico (KESSLER, 2009, p.117). Também, a partir das narrativas que surgem durante e depois da reconstrução do templo, grosso modo, nos livros bíblicos de Crônicas, Esdras-Neemias, abre-se espaço de reflexão sobre aspectos da formação do cânon hebraico e a pluralidade de materiais literários que o compuseram. Esse conteúdo literário contribuiu tanto para a confecção de uma memória que, quando narrada, pretende-se coletiva; quanto para gerar expectativas de um futuro idealizado (ou utópico). Em ambos os casos, a narrativa bíblica pretende imprimir no presente da comunidade, novos sentidos identitários, isto é, "os judaítas exilados vieram a desenvolver uma compreensão fundamentalmente nova de si mesmos" (CARR, 2014, 


\section{artigos}

\section{Samuel de Barros Gandara}

p.76, tradução própria)².

De particular interesse para a discussão aqui proposta, é durante o período babilônico que as elites judaítas, principalmente do grupo da dinastia davídica, desenvolveram uma percepção própria de seu afastamento da terra natal, com implicações teleológicas notáveis na posterior construção da narrativa do retorno (GLISSMANN, 2019, p. 90-156). Um elemento que bem exemplifica essa questão em Esdras-Neemias está relacionado à forma como o grupo de retornados identificou as comunidades judaítas remanescentes, que permaneceram em Judá durante o período exílico.

Nesse sentido, a narrativa bíblica, quando trata do exílio, do período de reconstrução de parte da cidade de Jerusalém e das novas configurações sociais e políticas derivadas do avanço do Império Aquemênida, é tensionada a propor uma memória que se articula sob tais condições históricas dos fluxos migratórios. No caso do livro de Esdras-Neemias, apesar do fenômeno multivocal percebido no material, existe uma trama abrangente que gira em torno de conflitos entre grupos sociais. Essas disputas, por sua vez, não acontecem apenas em torno do poder político e social, mas igualmente preocupam-se com a composição de uma memória. Ou seja, pretende-se demonstrar que a memória, enquanto recurso narrativo em Esdras-Neemias, não cumpre apenas uma função instrumental em confrontos de outra natureza, seja ela sócio-política, econômica ou patrimonial, mas é propriamente um espaço de poder. Nesse caso, os grupos sociais que estão dispostos no centro desse fenômeno memorialístico compõem uma comunidade mnemônica que identifica na narrativa um

\footnotetext{
${ }^{2}$ No original: "the judean exiles were coming to a fundamentally new undertanding of themselves"
} 


\section{artigos}

\section{Esdras-Neemias e a gestão da memória}

importante vetor de relações sociais. Segundo Ben Zvi, todos os grupos sociais são também comunidades mnemônicas, pois um elemento central de sua reprodução consiste em um compartilhamento de memórias sobre passado e futuro. Para ele, “o autoconceito de um determinado grupo social e a sua compreensão da realidade a sua volta está alicerçado no espectro das memórias que se compartilha entre os indivíduos" (BEN ZVI, 2019, p.7. tradução própria)³.

Pormenorizar essa questão significa avaliar as construções de memória em seus próprios termos, identificando na documentação diferentes mecanismos de gestão da memória, tais como: retórica teleológica, que mistura dimensões do passado, presente e futuro do grupo; procedimentos editoriais na documentação, que podem remanejar diferentes tradições literárias em prol da ideologia do grupo social; estabelecimento de uma linguagem e gramática da memória, que faz uso de uma narrativa acerca do passado do grupo para aferir sentidos de inclusão/exclusão ao grupo social). Também, contribui para identificar os fenômenos de memória como um vetor de conflitos sociais, e não apenas em sua instrumentalização com fins de outra natureza. Sendo assim, pode-se insistir que a memória possui um espaço próprio de disputas entre grupos que a desejam manipulá-la, viabilizando discursos variados que tendem a dialogar com estruturas de coesão interna do grupo, e que, portanto, estão constantemente associadas a questão das identidades coletivas. Portanto, é possível dizer que existe uma relação indissolúvel entre memória e identidade: para o historiador francês Philippe Joutard, a memória é, de fato, uma força de identidade (JOUTARD, 1996, p.367). Dessa relação entre os fenômenos identitários e a construção de uma memória coletiva

\footnotetext{
${ }^{3}$ No original, "Moreover, the self-understanding of a group and their understanding of the world around them is grounded on the world of memory they share".
} 


\section{artigos}

\section{Samuel de Barros Gandara}

verifica-se enquanto ambos coparticipam das mesmas estruturas criativas, pois, ao mesmo tempo que uma memória proporciona elementos para a geração de uma identidade, essa mesma impõe as predisposições e limites aos indivíduos de quais elementos do passado serão levados em conta na escolha dos símbolos e significados memoriais.

Isso fica visível em Esdras-Neemias, quando se percebe que as construções identitárias se utilizam de sentidos encontrados em um espectro de memória compartilhada pelo grupo social que as reivindica: no processo de confecção identitária judaíta são feitas as seleções estratégicas no registro memorial amplo compartilhado socialmente. Essas seleções buscam, sobretudo, por experiências coletivas, como o exílio e que são legitimadas por meio de discursos e representações desse passado comum, principalmente a partir de tradições literárias que tinham por objetivo descrever e interpretar essas experiências. Acredita-se que, no momento de composição de Esdras-Neemias, diferentes narrativas estavam disponíveis, e foram utilizadas enquanto dispositivos literários que não só ativam memórias dessas experiências, como também podem conferir novos sentidos mediante suas próprias circunstâncias históricas

Somado a esse debate, uma abordagem que leva em consideração a dimensão traumática de determinados conteúdos memoriais, percebe-se que a destruição da cidade e do templo, como consequência da política de deportação unidirecional ${ }^{4}$ adotada pelo Império Babilônico, significou a destruição de referenciais políticos,

\footnotetext{
${ }^{4}$ No caso assírio, as deportações seguiam múltiplos destinos, e, portanto, partia de uma lógica de cruzamento entre populações de diferentes localidades, visando uma menor possibilidade de mobilização contrária ao poder imperial. Já para o caso do Império Babilônico, sua estratégia diferia por estabelecer um destino único aos grupos conquistados, na própria região da Babilônia. Ver LIVERANI, 2014, pp. $185-246$.
} 


\section{artigos}

\section{Esdras-Neemias e a gestão da memória}

sociais e culturais importantes a sociedade judaíta. Sintética e respectivamente, a extinção da monarquia, a guerra, morte e deportação de parte da população e a destruição do templo religioso com a tomada de seus artefatos sagrados constituem eventos que geraram um ambiente favorável às produções literárias sob uma conjuntura traumática. Na terminologia do filósofo Paul Ricoeur, essa coletivização do trauma acontece pela capacidade da memória em se organizar enquanto “configuração narrativa" (RICOEUR, 2011). Ou seja, é possível afirmar que uma determinada percepção adotada para avaliar e classificar a experiência do exílio enquanto trauma social depende das interpretações e narrativas que a classificaram como tal. Esse caráter sociológico do trauma diz respeito à própria natureza interpretativa de tais eventos. Nas palavras de Roy Eyerman,

Trauma coletivo exige interpretação. Nada - não importa o quão impactante ou doloroso - é culturalmente 'traumático' por si mesmo. Interpretação e reconhecimento são processos culturais centrados na significação e que requerem comunicação e comunicadores (EYERMAN, 2019, p.4, trad. própria) 5 .

Na narrativa bíblica, trauma e memória são tangíveis a medida que um determinado conteúdo narrativo foi produzido com intenção de expressar os sentimentos e sentidos dos grupos que passaram pela experiência da deportação e da destruição de seus símbolos culturais e políticos e sociais. Isto é, os eventos históricos da interação de Judá com a política imperial babilônica engendraram uma construção interpretativa dos eventos que pode ser chamada de traumática, e não necessariamente porque tais

\footnotetext{
${ }^{5}$ No original: "collective trauma collective trauma required interpretation. Nothing- no matter how powerful or hurtful-was culturally "traumatic" in itself. Interpretation and acceptance are meaning centered cultural processes that require communication and communicators"
} 


\section{artigos}

\section{Samuel de Barros Gandara}

eventos possuem em si mesmos a capacidade de gerar um sentido cultural. A experiência histórica do exílio babilônico e posteriormente o movimento de retorno judaíta fizeram com que a dinâmica do grupo passe por transformações que, por sua vez, deram origem a diferentes formas de registros memoriais em forma de uma narrativa sobre o passado.

\section{Apontamentos gerais sobre a fonte}

Para testar alguns dos recursos de estudos de trauma e memória, primeiramente é necessário estabelecer alguns apontamentos gerais sobre a documentação de Esdras-Neemias. Esse procedimento tem como princípio, identificar tanto as tendências gerais da fonte como também delimitar suas especificidades. Grosso modo, alguns dos trechos que serão mencionados na análise fazem parte do livro canônico de nome Esdras-Neemias; na Bíblia Hebraica, encontram-se três grandes blocos de material literário, que são: a torá (que na tradução grega ficou conhecida como Pentateuco); os neviim (composto pela literatura profética); e, por fim, os ketouvim ("os Escritos") (RÖMER, 2016, p. 15). Nesse último conjunto, encontram-se as seções de livros poéticos (os Salmos, Provérbios e Jó); em uma segunda subdivisão estão os livros de Cantares, Rute, Lamentações, Eclesiastes e Ester. Por fim, na última seção desses Escritos, encontra-se o livro de Daniel, Esdras-Neemias e as Crônicas. No texto massorético, Esdras-Neemias aparece como uma unidade literária, enquanto que na era cristã o livro tenha experimentado algumas divisões - na LXX, acrescentasse o livro apócrifo grego de Esdras (= 1 Esdras); o material massorético recebia a nomenclatura de Esdras II. Já na versão latina, i.e Vulgata, ainda existe uma inserção do material apocalíptico de nome 4 Esdras (1 Esdras = Esdras; 2 Esdras = Neemias; 3 Esdras = 1 Esdras LXX; 4 Esdras) (ABADIE, 2010, p.703). Para as finalidades desse artigo, a fonte utilizada é o material massorético de Esdras-Neemias, através da versão traduzida para 


\section{artigos}

\section{Esdras-Neemias e a gestão da memória}

o português da Bíblia Hebraica disponível na Bíblia de Jerusalém .

É difícil datar com precisão o momento exato da confecção das narrativas de Esdras-Neemias, já que seu conteúdo é bem diversificado. A maior parte dos biblistas considera que os textos passaram por diferentes períodos de redação, e também de compilação final, mas em suma, aceita-se que a finalização aconteceu já no período Helenístico, por volta de 330 a.E.C (FRIED, 2017, p. 15). Em relação à questão da autoria, num primeiro momento, uma série de biblistas como M. Noth (1987) defendiam o argumento de que havia um único o autor para o livro das Crônicas, que era o mesmo autor tanto de Esdras, como de Neemias. Seu modelo consistia em análises linguísticas e teológicas, que posteriormente foram objeto de diferentes críticas por Japhet (1968) e Williamson (1985). Ambos apontaram para uma série de inconsistências nos modelos que enquadram um mesmo autor e/ou redator para essas fontes históricas. A solução proposta consistiu em avaliar Esdras-Neemias como originalmente um material fragmentado, composto por diferentes autores, mas que tardiamente passou por processos editorias que conferiram formas de "costura" no texto, principalmente por meio de elementos de continuidade entre as narrativas (BECKING, 2011, p. 4).

A crítica literária, seguindo uma divisão simples, dividiu o conteúdo de EsdrasNeemias em três blocos: 1) Esdras 1-6: marcada pelo bilinguismo (trechos em hebraico e aramaico), acredita-se que esse bloco seja o de redação tardia, como foco específico na reconstrução do Templo em Jerusalém (ABADIE, 2010, p.704). Seu contexto redacional reflete preocupações sacerdotais, semelhantes ao mesmo círculo que tonalizou o livro das Crônicas em seus processos finais de redação (WILLIAMSON, 1985). Nesse

\footnotetext{
${ }^{6}$ BÍBLIA DE JERUSALÉM: contendo antigo e novo testamento traduzido direto do original. $12^{\mathrm{a}}$ ed. São Paulo: Paulus, 2017.
} 


\section{artigos}

\section{Samuel de Barros Gandara}

primeiro ciclo narrativo encontra-se as primeiras tentativas por parte dos redatores bíblicos de acrescentar uma referência contextual histórica, por meio de um suposto edito de Ciro, o persa (538 a.E.C). A descrição da primeira onda de retornados sob liderança de Sasabassar é rapidamente contornada pela própria estrutura narrativa que, conforme demonstrou Japhet (1982), organizou o material em torno de um díptico de duas figuras: uma sacerdotal e outra secular (Zorobabel/Josué; Esdras/Neemias). Sendo assim, a atenção volta-se completamente para a atuação de Zorobabel e Josué na província de Judá, responsáveis por lançar as bases do santuário e reconstruir o Templo (Esd 1,1-4,5; 4,24a-6,22).

O segundo bloco narrativo (2), encontrado no intervalo de Esdras 7-10 e Neemias 9-8, é também conhecido como "memorial de Esdras - EM", pois alterna o relato dos acontecimentos entre uma primeira pessoa ("eu" - propondo um caráter autobiográfico) e na terceira pessoa ("ele" - compondo um estilo mais narrativo). Aqui, a narrativa parece situar-se mais bem definida entre os anos 460 a.E.C a 400 a.E.C, correspondendo ao reinado do monarca persa Artaxerxes I (SCARDELAI, 2012, p.46). A descrição da atividade religiosa é central, e indica a temática geral do material - contando com a inauguração do Templo e a celebração da Páscoa. Nessa composição, os personagens principais são Esdras, apresentando como escriba e sacerdote, e o grupo de retornados, denominado de "filhos do Exílio" (Esdras 7,7). O relato preocupa-se em centralizar a comunidade e seus conflitos, marcado por episódios dramáticos - como a suposta expulsão das "mulheres estrangeiras" (Esdras 9) e a purificação do povo por meio da leitura da Lei de Moisés (Esdras 10) (TALMON, 1997, p.384).

Por fim, o último material identificado é conhecido como o (3) “memorial de Neemias", composto por Neemias 1-7 e 10-13. Nesse trecho, são relatados os feitos de Neemias, que veio da capital do império Aquemênida, Susa à Jerusalém no vigésimo ano 


\section{artigos}

\section{Esdras-Neemias e a gestão da memória}

de Artaxerxes I (445 - 444 a.E.C) para empreitar a reconstrução da cidade e de suas muralhas (TALMON, 1997, p.385). Designado como governador da província de Judá (Neemias 5,14-19), Neemias enfrenta uma série de oposições internas (como o sumo sacerdote Eliasib - Neemias 13,4) e de outros "povos estrangeiros" - como Tobias, Sanabalat e Geshem (Neemias 6,1).

Em suma, mesmo que em Esdras exista um material essencialmente sacerdotal, ao se deter em temáticas relativas ao templo, a organização da classe sacerdotal, o culto javista, e a comunidade e em Neemias vigore uma perspectiva político-social, voltada para o reassentamento populacional na cidade de Jerusalém e a reconstrução das defesas da cidade através das muralhas (VANDERKAM; KRAEMER apud BECKING, 2011), percebe-se que as narrativas foram conscientemente trabalhadas de maneira conjunta por processos tardios de compilação. Isso implica conceber as narrativas de Esdras e Neemias como um produto final único, que deve ser entendido como uma narrativa contínua, assim como defende L. Fried em seu comentário ao livro de Esdras: “o produto final deve ser lido como um livro, isso inclui o trabalho de diversos autores e editores independentes, cuja escrita foi completamente entrelaçada" (FRIED, 2017, p.3).

Para os objetivos de análise nesse artigo, que tem como preocupação maior avaliar aspectos históricos da comunidade que produziu, transmitiu e consumiu esse material, será utilizada uma abordagem sincrônica do texto. A principal contribuição bibliográfica para essa abordagem pode ser encontrada nas obras de Eskenazi (1988, 2008) - em sua leitura de Esdras-Neemias, a autora compartilha da mesma perspectiva de Fried citada anteriormente, em que os dois livros devem ser encarados como uma única narrativa contínua. Mesmo diante de múltiplas vozes ou ecos de tradições 


\section{artigos}

\section{Samuel de Barros Gandara}

dissidentes, Fried e Eskenazi identificam uma unidade particular ao longo dessas diferenças, ou seja, apesar das aparentes incompatibilidades e divergências entres os livros bíblicos, é possível identificar uma harmonia e conformidade. De acordo com Eskenazi, os livros de Esdras e Neemias são “um artefato literário em que diferentes fontes combinaram-se em sentido e significado para expressar ideologias particulares" (ESKENAZI, 1988, p.74) Nesse sentido, mesmo diante de vozes dissonantes que podem emergir na narrativa, é possível identificar temas principais e seus desdobramentos em subtemas.

É importante perceber que a narrativa de Esdras-Neemias enquanto dispositivo narrativo que tenta dar conta de diferentes memórias, relatos autobiográficos, descrições de eventos históricos e documentos da chancelaria persa, o faz por uma percepção própria do passado de Judá e Jerusalém. A experiência do exílio foi um marco histórico que imprimiu nos redatores e editores do material de Esdras-Neemias uma dimensão étnico-sociorreligiosa particular, que se desenvolveu ao longo do período do judaísmo do Segundo Templo (SCARDELAI, 2012, p. 50). Nesses termos, conforme apontam os estudos de Eskenazi (1988, p. 648), alinhada à Japhet (1983), o período da Reconstrução também é marcadamente um momento de redesenhar os conteúdos identitários - para parte dessa documentação, por exemplo, “o verdadeiro Israel" inclui apenas os deportados. O exílio babilônico passa a ser um distintivo étnico, que estabelece tanto limites internos como externos da formação do grupo.

Na narrativa, essa comunidade judaíta é descrita nos entornos de um horizonte geográfico também idealizado, fruto dessa percepção exclusivista. De maneira esquematizada, Dozeman toma o modelo de H. Lefebvre, para refletir como o relato de Esdras-Neemias "produziu” a experiência pós-exilica de Judá. Para o autor, na província de Judá coexistem o espaço concreto, o concebido e o espaço vivo; tomados pelos 


\section{artigos}

\section{Esdras-Neemias e a gestão da memória}

autores bíblicos como: 1, Espaço concreto ou perceptível é aquele que faz menção ao amplo território governado e administrado por autoridades persas. Este é o espaço em que os diferentes códigos de lei (locais e imperiais) podem interagir, ou seja, no qual as políticas administrativas persas se fazem mais presentes; 2. Espaço concebido ou imaginário é aquele em que os laços sociais se estabelecem, quer de maneira harmoniosa, quer onde são flagrados conflitos de interesses. Nestes conflitos, pode ser identificada uma cosmovisão própria que está sendo proposta para a vida dessa comunidade em formação; 3. Por fim, um espaço vivo, no qual a memória coletiva pode ser mobilizada em nome de um novo ideal de comunidade. Isto é, produzir uma comunidade que apesar das experiências traumáticas do Exílio babilônico, encontrou uma nova forma de gerir as perdas, organizando a comunidade de retornados por princípios de uma narrativa que constrói um passado compartilhado por todos. (DOZEMAN apud SCARDELAI, 2012, p. 49).

\section{Esdras-Neemias: dispositivos de memória}

O percurso agora é o de identificar alguns dos recursos memoriais na narrativa de Esdras-Neemias, bem como sua ação na organização da comunidade de retornados por meio da narrativa. Para isso, serão selecionados trechos dispostos no primeiro bloco da documentação (i.e, Esdras 1-6). De maneira geral, a narrativa parte de uma perspectiva particular sobre o movimento de retorno, tendo sua âncora na experiência exílica; segue-se nos relatos a apresentação de diferentes personagens e tramas, que de modo geral giram em torno de um mesmo tema a ser desenvolvido: o reassentamento de grupos judaítas outrora na comunidade babilônica. Dentro dos objetivos desse grupo, está o estabelecimento de atividades religiosas, que envolvem a reconstrução do templo situado em Jerusalém (JAPHET, 2006). De certo modo, está 


\title{
artigos
}

\section{Samuel de Barros Gandara}

quase que subentendido na narrativa que a audiência possui conhecimento do exílio babilônico e das razões pelas quais o grupo teve de experimentar a destruição do Primeiro Templo, bem como o que originou o fim da monarquia e a deportação da terra de origem. Assim, o relato parece construir, de imediato, uma espécie de suspenção do caráter negativo do exílio, proporcionando uma forma de expectativa na audiência, que encontra na sequência dos eventos narrados a possibilidade de visualizar a superação do trauma por meio de esforços de grandes líderes: Zorobabel/ Josué, Esdras/Neemias.

O trecho a seguir de Esdras 1,1-3 é importante para observar esse movimento na estrutura narrativa e da própria concepção teleológica do redator bíblico,

\begin{abstract}
No primeiro ano de Ciro, rei da Pérsia, para cumprir a palavra de lahweh pronunciada por Jeremias, lahweh suscitou o espírito de Ciro, rei da Pérsia, que mandou proclamar de viva voz e por escrito, em todo o seu reino, o seguinte: "Assim fala Ciro, rei da Pérsia: lahweh, o Deus do céu, entregou-me todos os reinos da terra e me encarregou de construir-Ihe um Templo em Jerusalém, na terra de Judá. Todo aquele que dentre vós, pertence a seu povo, Deus esteja com ele e suba a Jerusalém, na terra de Judá, e construa o Templo de lahweh, o Deus de Israel - o Deus que reside em Jerusalém. (Bíblia de Jerusalém - Esdras 1,1-3).
\end{abstract}

De acordo com esses primeiros versículos, o Deus de Israel, lahweh, incitou o rei persa, Ciro I, a prescrever, já nos primeiros anos de seu reinado, um edito que permitisse o retorno de populações judaítas à Jerusalém. Para além disso, o decreto real ainda legitima que tal grupo de retornados reconstrua o templo de Jerusalém, assegurando os recursos e o suporte necessário para garantir a atividade. Diferentes comentaristas bíblicos já discorreram sobre a historicidade dos diversos documentos da chancelaria persa no material de Esdras-Neemias (GRABBE, 2006, p. 531-570). No caso desse primeiro edito de Ciro, suas particularidades estilísticas (os títulos e nomes, a língua utilizada em sua composição e a temática abordada) dificultam identificar 


\section{artigos}

\section{Esdras-Neemias e a gestão da memória}

como um documento originalmente persa. Todavia, por mais que esse trecho possa ter sido escrito e inserido na narrativa de Esdras 1 por um editor bíblico, Grabbe também identifica que a política e ação governamental nele mencionado é historicamente factível, principalmente se levarmos em conta as consequências da política imperial descrita no Cilindro de Ciro (GRABBE, 2006, p.544). Sendo assim, cabe a pergunta: qual a função de inserir um edito imperial com tais características logo no início da narrativa do retorno?

Nesses versículos iniciais, algumas coisas chamam a atenção: em primeiro lugar, essa possibilidade de retorno de judaítas mediante a autorização imperial configura um acontecimento histórico que é retratado à luz do cumprimento de um oráculo de um profeta bíblico. A narrativa constrói uma continuidade entre o passado do grupo e o seu presente por meio de predições de Jeremias, que são colocadas à prova. A autoridade da narrativa de Esdras-Neemias ancora-se no posicionamento de um edito imperial Persa ao lado da realização de uma tradição profética. Conforme observado por Smith-Christopher, esse recurso é algo programado: comparando com formas linguísticas encontradas em 1 Crônicas 5,26 e Isaías 19,2 (episódios que descrevem o Deus de Israel despertando sentimentos e ações que lhe apraz em autoridades régias estrangeiras), pode-se concluir que essa descrição cumpriu uma função sociopsicológica (SMITH-CHRISTOPHER, 2002, p.38-40). De um lado, seu papel social é tecer uma forma de identificação coletiva com a divindade, que é responsável pelo grupo e, de outro, sua característica psicológica é promover um sentimento de pertencimento a um determinado grupo social.

Ao afirmar que o edito deriva de uma vontade divina, prenunciada por um profeta, Esdras-Neemias evidenciam que lahweh não perdeu o controle da história de seu 


\section{artigos}

\section{Samuel de Barros Gandara}

povo. Isso também não deixa de demonstrar um certo mecanismo de sobrevivência da memória dos grupos judaítas, pois, se de um lado, dependem de fato da ação de uma autoridade régia estrangeira, de outro, (re)negociam o papel da divindade na memória do trauma do exílio. Ora, o sofrimento e a destruição compõem um meio pelo qual a comunidade pode se orientar e, assim,

Os editores de Esdras-Neemias representam uma teologia subversiva, uma agenda subliminar, que reserva o reconhecimento da autoridade exclusiva de Deus, enquanto mantém certa polidez para com as autoridades imperiais (SMITH-CHRISTOPHER, 2002, p. 45. tradução própria).

Do ponto de vista literário, essas tradições proféticas foram importantes para a construção de interpretações teológicas e teleológicas da experiência do exílio, desempenhando um papel importante na transformação e manutenção da relação do grupo com a divindade. De acordo com Schimid, fica evidente na narrativa de Esdras 1-6 que o processo de reconstrução do templo só obterá êxito se acompanhado do apoio profético; pode-se tomar de exemplo o versículo de Esdras 6,14, que diz

Os anciãos dos judeus continuaram a construir, com êxito, sob a inspiração do profeta Ageu e de Zacarias, filho de Ado. Terminaram a construção de acordo com a ordem do Deus de Israel e a ordem de Ciro e de Dario. (Bíblia de Jerusalém. Esdras 6,14).

O versículo acima deixa explícito que é somente no decorrer dos fluxos de retornados, com os grupos dos profetas Ageu e Zacarias, que as obras do templo puderam ser finalizadas (SCHIMID, 2013, p.206). Sendo assim, tradições proféticas que

\footnotetext{
${ }^{7}$ No original, Thus, the editors of Ezra-Nehemiah represent a subversive theology, a hidden transcript, that reserves recognition of authority to God alone, while maintaining a necessarily polite demeanor to the imperial representatives.
} 


\section{artigos}

\section{Esdras-Neemias e a gestão da memória}

emergem no contexto exílico como partes de Jeremias e Ezequiel, serviram de fundamento teleológico para a narrativa de Esdras-Neemias, que avaliam a história dos retornados como um cumprimento dos planos divinos. Essa forma literária de EsdrasNeemias encontra-se no limite entre concepções da história deuteronomista e a cronista, ou seja, conforme Schimid, foi "influenciada deuteronomisticamente é a estreita relação entre lei e bem-estar; próxima a teologia cronista encontra-se o alto apreço dedicado ao domínio persa" (SCHIMID, 2013, p.206).

Anteriormente, perguntava-se qual a função de inserir essa espécie de documento da chancelaria persa no discurso de reassentamento. Uma possível resposta é a de que a inserção do edito retroalimenta a própria tradição profética bíblica, bem presente no universo literário e religioso da comunidade deportada e também para a comunidade de retornados (BEN ZVI, 2013, p.75-102). Por outro lado, do ponto de vista das implicações sociais, essa narrativa pode ser caracterizada como um dispositivo de memória, pois engatilha uma espécie de expectativa social acerca do presente e futuro do grupo de retornados. Sua função é indicar os limites internos de uma construção identitária específica: a reconstrução do templo cabe exclusivamente aos descendentes de deportados no exílio. Retomando o fato de que esse bloco narrativo da documentação é de composição tardia, ou seja, que é melhor situada no final do período persa, existe um esforço da narrativa em jogar luz à reconstrução do templo. Tal empreendimento não é apenas de necessidade religiosa, mas também política. Ao dialogar com o universo de esperanças em torno da restauração, Esdras 1-6 serve como um dispositivo de memória, que (re)negocia diretamente com a memória do período monárquico, no qual o templo era de fato um importante espaço de relações sociais. Por meio da interpretação conferida aos eventos traumáticos da destruição do templo e da cidade, a narrativa propõe uma comunidade de retornados que deve identificar 


\section{artigos}

\section{Samuel de Barros Gandara}

na reconstrução do templo a sua própria experiência de reassentamento e de identidade judaíta. Sendo assim, por meio do templo, não apenas o trauma do exílio pode ser superado, mas o cumprimento de um novo "êxodo", que aponta para a posse da terra, pode ser resgatado.

Avançando um pouco na documentação, em Esdras 2,1-2a, Zorobabel, acompanhado de Josué e outros dez condutores (formando o emblemático número das doze tribos) são apresentados liderando um grupo de deportados. O texto diz,

Eis os cidadãos da província que voltaram do cativeiro e do Exílio, aqueles que Nabucodonosor, rei de Babilônia, deportara para Babilônia; voltaram para Jerusalém e para Judá, cada um para a sua cidade. Eles voltaram com Zorobabel, Josué, Neemias, Saraías, Raelaías, Naamani, Mardoqueu, Belsã, Mesfar, Beguai, Reum, Baana (Bíblia de Jsrusalém.Esdras, 1,1-2a).

O nome Zorobabel (Zêr-Bâbili) tem um significado próximo de "semente da Babilônia" (STRONG, 1996), o que já indica um recurso programático e consciente da narrativa, por meio do qual, elementos de caracterização identitária do grupo tornam-se explícitas. De um lado, tanto essa semântica quanto a apresentação das origens do grupo, conferem ao grupo de retornados uma descendência direta dos judaítas que residiam em Judá no momento da deportação babilônica. De outro, a narrativa enfatiza o vínculo de filiação com os residentes dos territórios babilônicos, sugerindo que tal grupo manteve uma mesma identidade coletiva (sem explicitar o que assegurou essa continuidade). A narrativa segue descrevendo as primeiras ações do grupo, que contam inclusive com o arrecadamento de bens e tesouros para a reconstrução do Templo de Deus (Esdras 2,64-70). O relato também sugere toda uma estrutura de corpo sacerdotal, contando com cantores, porteiros, levitas e sacerdotes. É somente em Esdras 3 que temos a primeira descrição da reconstrução de um altar em que foram oferecidos holocaustos em nome de lahweh. Ainda, menciona-se a celebração de 


\title{
artigos
}

\section{Esdras-Neemias e a gestão da memória}

uma festividade importante para o judaísmo do Segundo Templo - a Festa das cabanas. O episódio aparece da seguinte forma:

\begin{abstract}
Restabeleceram o altar em seu lugar - apesar do medo que tinham dos povos das terras e ofereceram sobre ele holocaustos a lahweh, holocaustos da manhã e da tarde; Celebrou -se a festa das Tendas, como está prescrito, com o número de holocaustos cotidianos que está determinado para cada dia; cantaram a lahweh louvores e ações de graças: "Pois ele é bom, pois eterno é seu amor" por Israel. E o povo todo aclamava em altas vozes, louvando a lahweh, porque eram lançados os alicerces do Templo de lahweh. Contudo, muitos sacerdotes, muitos levitas e chefes de família, já idosos e que tinham visto o primeiro Templo, choravam em alta voz enquanto, sob suas vistas, se punham os alicerces, mas muitos gritavam de alegria e júbilo E ninguém podia distinguir os gritos de alegria do rumor das lamentações do povo; pois o povo gritava em altos brados e o vozerio se podia ouvir de longe. (Bíblia de Jerusalém. Esdras 3,3-4 [...] 11-13).
\end{abstract}

Em um primeiro momento, o que chama atenção nesse relato é que apesar da ausência do templo (até esse momento, a narrativa sugere que apenas os alicerces estavam sendo lançados), as expressões religiosas são marcadas por uma liturgia que espelham a dedicação do Primeiro Templo, no período da monarquia davídica. O relato parece ecoar a tradição deuteronomista de 1 Reis 8: o altar é construído - a comunidade é organizada em torno do Templo, onde são oferecidos os sacrifícios - é celebrada a Festa das Tendas. De certo modo, a narrativa de reconstrução do Segundo Templo vê na tradição deuteronomista um dispositivo de memória importante, pois a obra de reconstrução do templo depende agora do grupo outrora exilado. Essa ação coletiva é legitimada enquanto agir conforme práticas semelhantes a tradição monárquica anterior, em que o templo desempenhava o papel central de expressão religiosa javista. Outro elemento de tradição deuteronomista importante para esse breve relato de Esdras-Neemias encontra-se em paralelo com as prescrições de holocausto encontradas Números 28, 3-8. Esse capítulo comporta um bloco importante de material sacerdotal, que oferece especificações cultuais, prescreve as práticas de sacrifícios 


\title{
artigos
}

\section{Samuel de Barros Gandara}

para diferentes ocasiões e a agenda das festividades para a segunda geração que deveria adentrar na terra prometida (RÖMER, 2010, p.249-251). Essa espécie de espelho memorial que a narrativa de Esdras-Neemias produz em relação a descrição no primeiro livro de Reis é justamente um esforço do editor tardio em redirecionar a atividade religiosa de Judá para sua expressão no interior de uma estrutura templária em Jerusalém: a narrativa é composta de maneira a

\begin{abstract}
Mostrar as conexões entre o retorno dos exilados e a narrativa do Êxodo. Também, apontar como a dedicação do templo reconstruído relaciona-se com a construção do templo original, nos tempos de Salomão. Demonstrar esse aspecto de continuidade é de importância primordial, pois a validade do Segundo Templo deriva de sua semelhança com o projeto salomônico. (BOLIN, 2017, p.685. tradução própria) ${ }^{8}$.
\end{abstract}

\section{Esdras-Neemias e a gestão da memória em crise}

Até o momento, foram apresentados alguns recursos narrativos que mobilizam dispositivos de memória social e coletiva, tais como: interesses do relato cronista em relação ao Império Persa, a tradição profética no que diz respeito a concepção teleológica do exílio babilônico, uma semântica identitária na descrição do grupo de retornados e materiais sacerdotais da historiografia deuteronomista na organização do templo. Porém, conforme apontado brevemente na seção introdutória que tratava das particularidades dessa documentação, o relato bíblico da reconstrução é reconhecidamente dinâmico e multivocal, pois envolveu múltiplos processos redacionais e editorias. Sendo assim, cabe avaliar também momentos em que a narrativa é tensionada por conflitos de memórias.

\footnotetext{
${ }^{8}$ No original, The author of Ezra-Nehemiah is at pains to show connections between the return of the exiles and the exodus as well as the dedication of the rebuilt temple with the building of Solomon's original. Continuity is of prime importance, for in its resemblance to its Solomonic prototype the new temple derives its validity.
} 


\section{artigos}

\section{Esdras-Neemias e a gestão da memória}

Tendo como base ainda o trecho citado anteriormente, de Esdras 3, se percebe que, se de um lado a natureza desse relato inicia de maneira coesa, em Esdras 3,1213, a narrativa cria uma espécie de anticlímax. Entre os indivíduos que compunham o grupo de exilados, são descritos dois ânimos quando diante da reconstrução dos alicerces do templo. De um lado, há uma parcela do grupo de retornados que, ainda que participantes da empreitada, lamentava-se, pois rememorava o prestígio do Primeiro Templo, destruído na ação babilônica. De outro, as novas gerações, os que estão vindo direto da comunidade de exilados, são descritos com júbilo diante da possibilidade de construir um novo templo. Nesse momento, o relato distingue esses dois grupos por meio de uma temporalidade memorial, ou seja, o que os separa não é apenas a forma como reagem à reconstrução do Templo. O duplo ânimo é causado pois uma parte do grupo reivindica o primeiro templo como uma memória paradigmática, enquanto os demais valorizam a experiência de construir um novo templo. Colocando de outro modo, o texto sugere que o vetor de conflitos de sentimentos entre o grupo é uma memória do templo, em que existe diferentes formas de lidar com o passado do grupo. Esse fenômeno memorial que emerge na narrativa não parece ser acidental, pelo contrário, parece ser uma forma de gerir uma memória em crise. Essa crise, parece ser provocada pela própria experiência do retorno e a pluralidade de sentidos que isso pode suscitar no interior do grupo - inclusive sinaliza para a existência de um conflito de gerações de em condições migratórias semelhantes as vistas em Judá no pós-exilio (SOUTHWOOD, 2015, p. 322-335).

Nessa perspectiva, o relato parece estar gerindo uma memória em crise, que está dicotomizada entre um passado idealizado, subsidiado pela memória do Primeiro Templo, e o presente da reconstrução do Segundo Templo. As condições de reassentamento judaíta no pós-exilio criaram a possibilidade de ter um futuro do grupo em 
Samuel de Barros Gandara

que gradualmente o Primeiro Templo tivesse sua memória suplantada por uma outra. Por essa abordagem, é possível nuançar duas camadas de memória em rearranjo: a primeira reflete o conteúdo de sentidos daqueles que se recordam do Primeiro Templo, mas que devido ao exílio babilônico perderam esse referencial com a destruição. A segunda, emerge de uma experiência religiosa sem templo, e que a partir do retorno, pode construir uma nova estrutura templária ${ }^{9}$. Nesses termos, a narrativa da vazão a uma espécie de dispositivo de resiliência memorial que está lidando tanto com o passado como com o presente do grupo. Por meio dos recentes desenvolvimentos de uma hermenêutica do trauma, Schreiter defende que a principal relação entre memória e trauma consiste na tarefa da primeira em criar uma coerência narrativa (SCHREITER, 2016, p.200). O autor toma por base a reflexão de David Janzen (2012) sobre o caráter dissociativo de eventos traumáticos, isto é, de gerar configurações narrativas limitadas do ponto de vista de construir discursos coesos. Na obra The Violent Gift, Janzen conclui que, nesses casos, a

Linguagem se desprende da experiência e perde sua capacidade de dar forma e significado à experiência. O passado e o presente se tornam desconectados, a própria temporalidade é suprimida. Há uma perda da capacidade de colocar a experiência traumática em um quadro de causalidade e ética, destruindo a capacidade de produzir sentido (SCREITER, 2016, p.196. Tradução própria). ${ }^{10}$

\footnotetext{
${ }^{9}$ Embora escape dos limites da investigação aqui proposta, contrastar a celebração da Festa das Cabanas descrita em Esdras 3, com seu paralelo em Neemias 8 também acrescentaria um exemplo desse sentido. Em Neemias 8,1-3, a comunidade se reúne fora dos limites do templo, defronte da porta das Águas; de um lado, mais uma vez fica evidente que para o editor de Esdras 1-6, a expressão da religiosidade javista vincula-se não a penas à comunidade de retornados, mas também ao aparato do templo. De outro, trechos da narrativa como esse apontam para formas de expressão religiosa que não necessariamente dependem dessa mesma estrutura, pois encontram-se baseadas na celebração coletiva mediada pela Lei de Moisés.

${ }^{10}$ No original, "language becomes unmoored from experience and loses its capacity to give form and meaning to experience, how past and present become disconnected, how temporality itself is suppressed, and how the loss of capacity to place traumatic experience in a framework of causality and ethics destroys the capacity for making meaning".
} 


\section{artigos}

\section{Esdras-Neemias e a gestão da memória}

Segundo Schreiter isso pode ser superado a medida que a memória é capaz de conferir coerência aos conteúdos fragmentados da experiência traumática. Então se torna um obstáculo. Por meio dos trabalhos de Jan Assman (2006) e Jeffrey Alexander (2012), o autor nota um ponto de convergência importante para avaliar a relação entre memória e trauma: os trabalhos de memória cultural de Assman e de trauma cultural de Alexander concordam quanto as possibilidade da memória em tecer narratividade, em forma de cadeias de sentidos e coerência que faltam aos discursos traumáticos. Para eles, a memória traumática é um obstáculo à identidade do grupo, até possa ser absorvida por uma rede de memória estável. Essa estabilidade diz respeito a um enquadramento narrativo que pode ser chamado de resiliente, pois geriu a instabilidade provocada pelo discurso traumático.

Retomando a questão dos diferentes ânimos descritos diante dos alicerces do Primeiro Templo, uma questão pertinente que se pode fazer é, qual a necessidade do relato em manter essa dicotomização? E mais, existiria alguma função social em manter essa experiência de contestação de memória, sob o risco de expor diferentes estratos de memória que, à primeira vista, estão em conflito? Duas hipóteses são sugeridas, e se trabalhadas conjuntamente podem contribuir para ampliar a percepção dessa narrativa enquanto um fenômeno próprio de gestão de uma memória instável. Em primeiro lugar, no nível êmico da narrativa, parece haver uma demanda por explicitar, ainda que brevemente, essa permanência de um lastro memorial mantido por uma pequena parcela do grupo de exilados. Ao grupo dessa geração mais antiga cabe a função de assegurar a manutenção desse passado, que se comporta como um paradigma para o Segundo Templo. Todavia, enquanto passado rememorado, seu conteúdo não compreende um conjunto fixo de narrativas, relatos e valores, mas sim um 


\section{artigos}

\section{Samuel de Barros Gandara}

universo flexível de sentidos que passará por distintas e complexas formas de (re)significação à luz das novas demandas geradas pela alteração significativa das condições históricas. O que parece estar em jogo, nesse caso, é a tentativa da narrativa em gerir a perda do templo, administrar um estrato de memória que reluta contra o esquecimento.

Nesse sentido, a narrativa bíblica opta não pelo silêncio, mas em expor a negociação entre essas memórias, ainda que isso demonstre certa homogeneização em andamento - provavelmente com vistas a fortalecer a coesão de um projeto identitário em construção no contexto de reassentamento. Uma possível forma de lidar com esse problema é identificar a dicotomia lamento/júbilo apresentada anteriormente por meio do conceito de luto utilizado pela leitura que o filósofo Paul Ricoeur faz de Freud. A leitura hermenêutica da memória de Ricoeur vê no pensamento psicanalítico de Freud, uma possibilidade de lidar com a questão do trabalho da memória do ponto de vista do historiador. A base dessa reflexão está em utilizar o conceito de recalque e luto para abrir um horizonte de significados em narrativas que lidam diretamente com o universo do não dito. Em uma acepção freudiana, o conceito de luto adquire sentido enquanto encarado como um mecanismo de renunciar o passado, ou seja, de transformar uma perda em reconciliação, e assim, transferir o foco da libido individual para outro objeto. Em outras palavras, o luto (contrário à melancolia que leva à repetição da experiência da perda) é a garantia de superação daquilo que se perdeu. Quando utilizados por Ricoeur, esses conceitos contribuíram para seu empreendimento em lidar com os traumatismos coletivos e quanto à relação complexa entre memória e esquecimento. Destarte, aquilo que Ricoeur denomina de feridas da memória coletiva (RICOEUR, 2007, p.92) é uma referência tanto à noção do objeto que se perdeu, como para os espaços de reconciliação, que em última instância, significa 


\title{
artigos
}

\section{Esdras-Neemias e a gestão da memória}

apontar a cura (ou resiliência) de uma memória traumatizada, enferma. Nas palavras do filósofo francês,

\begin{abstract}
É a constituição bipolar da identidade pessoal e da identidade comunitária que, em última instância, justifica estender a análise freudiana do luto ao traumatismo da identidade coletiva. Pode-se falar em traumatismos coletivos e em feridas da memória coletiva, não apenas num sentido analógico, mas nos termos de uma análise direta. A noção de objeto perdido encontra uma aplicação direta nas "perdas" que afetam igualmente o poder, o território, as populações que constituem a substância de um Estado. As condutas de luto, por se desenvolverem a partir da expressão da aflição até a completa reconciliação com o objeto perdido, são logo ilustradas pelas grandes celebrações funerárias em torno das quais um povo inteiro se reúne (RICOEUR, 2007, p.92).
\end{abstract}

Desse modo, esse primeiro bloco da narrativa de Esdras parece justamente estar lidando com esse sentimento de luto de parte do grupo dos exilados, e que, portanto, deve haver um período de reconciliar o passado e presente. As condições históricas de reassentamento abriram margem para um processo de repensar a identidade judaíta. Esse pequeno relato de Esdras 3 é o suporte narrativo de um fenômeno de memória que está em contato direto com a estruturas internas de coesão do grupo. Essa dicotomia descrita nos termos daqueles que lamentam por se lembrarem do passado em relação aos que celebram o futuro é um dispositivo de gerir as instabilidades e contestações da memória. Nesse caso, a tentativa de apaziguamento é mediada pela narrativa que desloca a esperança do grupo daquilo que foi o passado, o objeto perdido, para o futuro, onde as possibilidades estão colocadas e dependem da ação do grupo para garantir o sucesso do empreendimento. Em outras palavras, mais do que uma tentativa de silenciar uma memória da importância do Primeiro Templo, esse relato dos primeiros grupos de retornados judaítas liderado por Zorobabel lida com ela projetando-a dentro da nova identidade em formação. Para esse grupo, deve existir a emergência de um projeto identitário que não se orienta mais apenas pela 


\section{artigos}

\section{Samuel de Barros Gandara}

memória da monarquia, da terra e do templo, mas sobretudo da experiência de solidariedade comunitária desenvolvida ao longo da experiência do exílio.

\section{Considerações finais}

Ao longo dessa breve investigação em trechos de Esdras-Neemias, foi possível identificar uma relação imbricada entre memória, narrativa e práticas sociais. Dentro dos objetivos teóricos, pretendeu-se demonstrar que o universo simbólico que constrói a experiência histórica de grupos sociais é marcadamente um domínio de conflitos, disputas e negociações. Particularmente no trato da documentação, no bloco de Esdras 1-6, foi possível detectar que a narrativa faz uso de diferentes dispositivos de memória como mecanismo de dialogar com o presente, passado e até o futuro do grupo de judaítas exilados, que puderam retornar a Judá. Esse fenômeno de memória não consiste em um conflito instrumentalizado por discursos políticos ou econômicos, mas é propriamente um espaço de poder que permeia o tecido social. Nesse caso, o funcionamento do novo templo parece ser o epicentro dessa aporia, no qual os grupos sociais disputam esse espaço de poder concomitantemente à gestão da memória. Os dispositivos memoriais mobilizados giram em torno de interpretações teológicas e teleológicas da experiência exílica, evidenciando o caráter dinâmico desse processo. Esse redesenhar de discursos e narrativas sobre presente, passado e futuro encontrase tensionado pelas condições históricas do retorno, que reconfiguraram a composição de grupos das elites locais em Judá.

Por fim, foi possível verificar que que a orientação da organização e reprodução social do grupo de exilados ocorre também mediante narrativas. São elas que são capazes de construir e (re)negociar sentidos e valores que conduzem as estruturas internas e externas do grupo. A capacidade de nomear, de formular e estabelecer os 


\section{artigos}

Esdras-Neemias e a gestão da memória

limites do grupo é uma importante modalidade de poder, que se encontra no interior de um aparelho narrativo. De certo modo, Esdras 1-6 exemplifica o teor de demais episódios importantes que compõe todo o teor identitário da narrativa de EsdrasNeemias: os grupos mencionados na documentação estão disputando, junto de questões políticas e econômicas, uma memória duplamente orientada. Em primeiro lugar, volta-se para interpretar o passado do grupo, ao mesmo tempo que se desdobra em uma prática de projeto identitário para o futuro da comunidade de retornados. Existe, portanto, uma necessidade de lidar com um fenômeno multivocal de memórias e discursos a respeito do passado, pois ao longo dos assentamentos judaítas do século V AEC, diferentes grupos puderam se (re)organizar em torno de suas próprias construções identitárias.

Referências bibliográficas

ABADIE, P. Esdras-Neemias. In: RÖMER; MACCHI; NIHAN (eds). Antigo Testamento: história, escritura e teologia. São Paulo: Edições Loyola, 2010.

ALEXANDER, J. Trauma: a Social Theory. Cambridge: Polity, 2012.

ASSMAN, J. Religion and Cultural Memory. Stanford: Stanford University Press, 2006.

BEN ZVI, E. Social Memory among the Literati of Yehud. Berlim: De Grutyer, 2019.

- Prophetic memories in the Deuteronomistic Historical and the Prophetic Collections of Books. In: JACOBS; PERSON (eds.), Israelite Prophecy and the Deuteronomistic History. Atlanta: SBL, 2013.

BECKING, B. Ezra, Nehemiah, and the Construction of Early Jewish Identity. 1 ed. Tübingen: Mohr Siebeck, 2011.

BERLEJUNG, A. New life, new skills, and new friends in exile: the loss and rise of capitals of the Judeans in Babylonia. In: FINKELSTEIN (ed). Alphabets, texts and artefacts in the Ancient Near East: Studies Presented to Benjamin Sass. Paris: VanDieren, 2017. p. 12- 


\section{artigos}

Samuel de Barros Gandara

46.

BOASE, E. Bible through the Lens of Trauma. Atlanta: SBL, 2016.

BOLIN, T. The Books of Ezra and Nehemiah. In: DURKEN (ed.) New Collegeville Bible Commentary. Minnesota: Liturgical Press, 2017.

CARR, D. Holy Resilience: the bible's traumatic origins. London: Yale University Press, 2014.

ESKENAZI, T. In na Age of Prose: Approach to Ezra-Nehemiah. Atlanta: SBL, 1988.

Unity and Disunity in Ezra-Nehemiah: responses and reflections In: BODA;

REDDIT (eds.) Unity and Disunity in Ezra-Nehemiah. Sheffield: Sheffield Phoenix Press, 2008. p. 315-328.

EYERMAN, R. Memory, Trauma and Identity. London: Palgrave Macmillan, 2019.

FRIED, L. Ezra: a commentary. Sheffield: Sheffield Phoenix Press, 2017.

GLISSMANN, V. Out of Exile, not out of Babylon: the Diaspora Theology of the Golah. Luwinga: Mzuni Press, 2019.

GRABBE, L. Ezra - Nehemiah. London: Routledge, 1998.

. The Persian Documents in the Book of Ezra: are they authentic? In: LIPSCHITS;

OEMING (eds.). Judah and the Judeans in the Persian Period. Indiana: Eisenbrauns, 2006.

JANZEN, D. Trauma and the Failure of History: Kings, Lamentations and the Destruction of Jerusalem. Atlanta: SBL, 2019.

- The Violent Gift: trauma's subversion of the Deteronomistic History's Narrative. London: T\&T Clark, 2012.

JAPHET, S. The relationship between Chronicles and Ezra-Nehemiah. In: Supplements to Vetus Testamentum. Leiden Brill, 1968.

. Sheshbazzar and Zerubbabel - against the background of the Historical and

Religious Tendencies of Ezra-Nehemiah. Zeitschrift für die Alttestamentiche 


\section{artigos}

Esdras-Neemias e a gestão da memória

Wissenschaft. Vol 94, Berlin, 1982, p. 66-98.

. Biblical Historiography in the Persian Period. World History of the Jewish People. Vol 6. Jerusalem, 1983. p. 176-202.

From the Rivers of Babylon to the Highlands of Judah: Collected Studies on the Restoration Period. Winona Lake: Eisenbrauns, 2006.

JOUTARD, P. Memory, Force of Identity. In: NORA (ed.) Realms of Memory: the construction of the French past. New York: Columbia University Press, 1996.

KESSLER, R. História Social do Antigo Israel. São Paulo: Paulinas, 2009.

LIVERANI, M. Para além da Bíblia: História Antiga de Israel. São Paulo: Paulus, 2014.

NOTH, M. The Chronicler's History. Sheffield: Sheffield Academic Press, 1987.

REDE, M. Al-Yahudu: os arquivos do exílio babilônico. Arquivo Maaravi - Revista digital de Estudos Judaicos da UFMG. Belo Horizonte, v.13, n.25, nov. 2019.

RICOEUR, P. A memória, a história, o esquecimento. Campinas: Editora da Unicamp, 2007.

Tempo e narrativa (vol I, II, III). São Paulo: WMF Martins Fontes, 2011.

RÖMER, T. Números In: RÖMER; MACCHI; NIHAN (eds.), Antigo Testamento: história, escritura e teologia. São Paulo: Edições Loyola, 2010. p. 242-259.

A origem de Javé: o Deus de Israel e seu nome. São Paulo: Paulus, 2016.

SCARDELAI, D. O escriba Esdras e o Judaísmo: Um estudo sobre Esdras à luz da tradição judaica. São Paulo: Paulus, 2012.

SCHREITER, R. Reading Biblical Text through the Lens of Resilience In: BOASE; FRECHETTE (eds.) Bible through the Lens of Trauma. Atlanta: SBL, 2016. p.193-208.

SCHIMID, K. História da Literatura do Antigo Testamento: uma introdução. São Paulo: Edições Loyola, 2013.

SMITH-CHRISTOPHER, D. A Biblical Theology of Exile. Minneapolis: Fortress Press, 2002. 


\section{artigos}

Samuel de Barros Gandara

SOUTHWOOD, K. The Impact of the Second and Third-Generation Returnees as a Model for Understanding the Post-Exilic Context In: STÖKL; WAERZEGGERS (eds.) Exile and Return: the Babylonian Context. Berlin: De Grutyer, 2015.

STRONG, J. The New Concordance of the Bible. Tenesse: Thomas Nelson Publishers, 1996.

TALMON, S. Esdras e Neemias In: ALTER; KERMODE (eds). Guia Literário da Bíblia. São Paulo: Editora Unesp, 1997.

WILLIAMSON, H. Ezra and Nehemiah. In: World Biblical Comentary (vol. 16). Nashville: Thomas Nelson Inc, 1985. 